\title{
Alectinib for choroidal metastasis in a patient with crizotinib-resistant $A L K$ rearranged positive non-small cell lung cancer
}

This article was published in the following Dove Press journal:

OncoTargets and Therapy

3 June 2015

Number of times this article has been viewed

\author{
Yusuke Okuma ${ }^{1,2}$ \\ Yuichiro Tanaka ${ }^{3}$ \\ Tina Kamei ${ }^{1}$ \\ Yukio Hosomi' \\ Tatsuru Okamura' \\ 'Department of Thoracic Oncology \\ and Respiratory Medicine, Tokyo \\ Metropolitan Cancer and Infectious \\ diseases Center Komagome Hospital, \\ ${ }^{2}$ Division of Oncology, Research \\ Center for Medical Sciences, The \\ Jikei University School of Medicine, \\ ${ }^{3}$ Department of Ophthalmology, Tokyo \\ Metropolitan Cancer and Infectious \\ diseases Center Komagome Hospital, \\ Tokyo, Japan
}

\begin{abstract}
Choroidal metastasis is rare in cancer patients. Small molecules of molecular targeted agents for lung cancer with actionable mutations were reported to be palliated for symptoms caused by choroidal metastasis. Visual disturbance by choroidal metastasis significantly decreases quality of life during the patient's remaining lifespan; therefore, radiotherapy or laser photocoagulation is proposed with consensus. However, improvement in survival with matched molecular targeted agents for oncogenic driver mutations reminds us to also be concerned with late treatment toxicities. A 30-year-old female patient previously treated with crizotinib harboring ALK rearranged non-small cell lung cancer complained of visual disturbance, fever, and bone pains undergoing anti-PD-1 antibody treatment. A decreased proportion of ALK fusion was demonstrated by fluorescence in situ hybridization in liver metastasis compared to the primary site in a chemo-naïve state. She was diagnosed with low vision, choroidal metastasis and retinal detachment. Therefore, she started alectinib treatment and both her ocular and systemic symptoms were palliated in a week. Later, she temporarily discontinued alectinib because of skin rash although the choroidal metastasis and retinal detachment resolved and she regained low vision completely at 2 weeks. She obtained partial response with alectinib for more than 5 months after recovering from skin rash.
\end{abstract}

Keywords: lung cancer, $A L K$ rearrangement, alectinib, choroidal metastasis, molecular targeted agents, crizotinib-resistant

\section{Introduction}

Choroidal metastasis is a rare distant metastatic location in cancer patients. With respect to lung cancer, the main metastatic lesions involve the lung, brain, and bone. ${ }^{1}$ Lung cancer is the leading cancer of choroidal metastasis in male patients, breast cancer in female patients, and adenocarcinoma by histological subtype. ${ }^{2-5}$ The consensus treatment for metastasis to the orbit is radiotherapy mainly aimed at palliative intent to prevent disturbing eye symptoms. However, the long-term complications resulting from radiotherapy is problematic in the era of longer survival for advanced solid tumors. ${ }^{6}$ Therefore, the strategy of treatment selection is crucial on diagnosis of choroidal metastasis. Some small molecules of targeted therapy had been reported to be active for choroidal metastasis of advanced non-small cell lung cancer (NSCLC). ${ }^{7,8}$

We herein report a patient having choroidal metastasis of crizotinib-resistant $A L K$ rearranged NSCLC successfully treated with alectinib.

\section{Case report}

A 30-year-old female harboring $E M L 4 / A L K$ rearranged advanced NSCLC with liver and bone metastases presented with visual disturbance with a left ocular black spot, 
within a year of undergoing chemotherapy at our institution (Figure 1A, B). She underwent first-line crizotinib for 6 months with partial response (PR), followed by four cycles of cisplatin/pemetrexed for 4 months with PR. At diagnosis, 70\% EML-4/ALK rearrangement via fluorescent in situ hybridization was revealed in the primary pulmonary site. However, hepatic biopsy at progression before third-line treatment revealed a decline of $E M L-4 / A L K$ rearrangement to $20 \%$. Expression of PD-L1 (programmed death-ligand 1) was also seen which lead to the initiation of third-line treatment with the PD-1 (programmed cell death-1) targeted therapy.

An ophthalmologist diagnosed left choroidal metastasis with retinal detachment upon initiating treatment of PD-1 targeted therapy and her visual acuity was 0.6 in the right eye and 0.4 in the left. The choroidal metastatic tumor was an irregular, marginal, white elevated lesion with 5 disc diameters in size in the left ocular fundus (Figure 2A, C, E). An exudative fluid was seen under the retina representing a retinal detachment. Two weeks later, systemic symptoms, including fever, bone pains, arthralgia, and visual disturbance were exacerbated. A second observation by the ophthalmologist showed clinically progressive disease of the left choroidal metastasis and she discontinued PD-1 targeted therapy and started alectinib (Alecensa ${ }^{\circledR}$ ) treatment.

In a week, both systemic symptoms and low vision were palliated and the choroidal metastasis with retinal detachment was also improved (Figure 2B, D, F). Multiple liver metastatic sites also decreased in size and were assessed as showing PR according to the response evaluation criteria in solid tumors (RECIST version 1.1 $)^{9}$ (Figure 1C, D). At the second week, her vision was completely recovered, however, she temporarily discontinued alectinib after 2 weeks because of skin rash due to alectinib and concurrently resumed alectinib and antihistamine. Her skin rash did not reappear and she sustained PR with improved eye sight for more than 5 months.

\section{Discussion}

The prevalence of symptomatic choroidal metastasis in cancer patients is approximately $1 \%-3 \%$, whereas a prevalence of $9 \%-12 \%$ is reported based on autopsy studies. ${ }^{10,11}$ Choroidal metastases from lung cancer are reported in $7.1 \%$ of autopsy
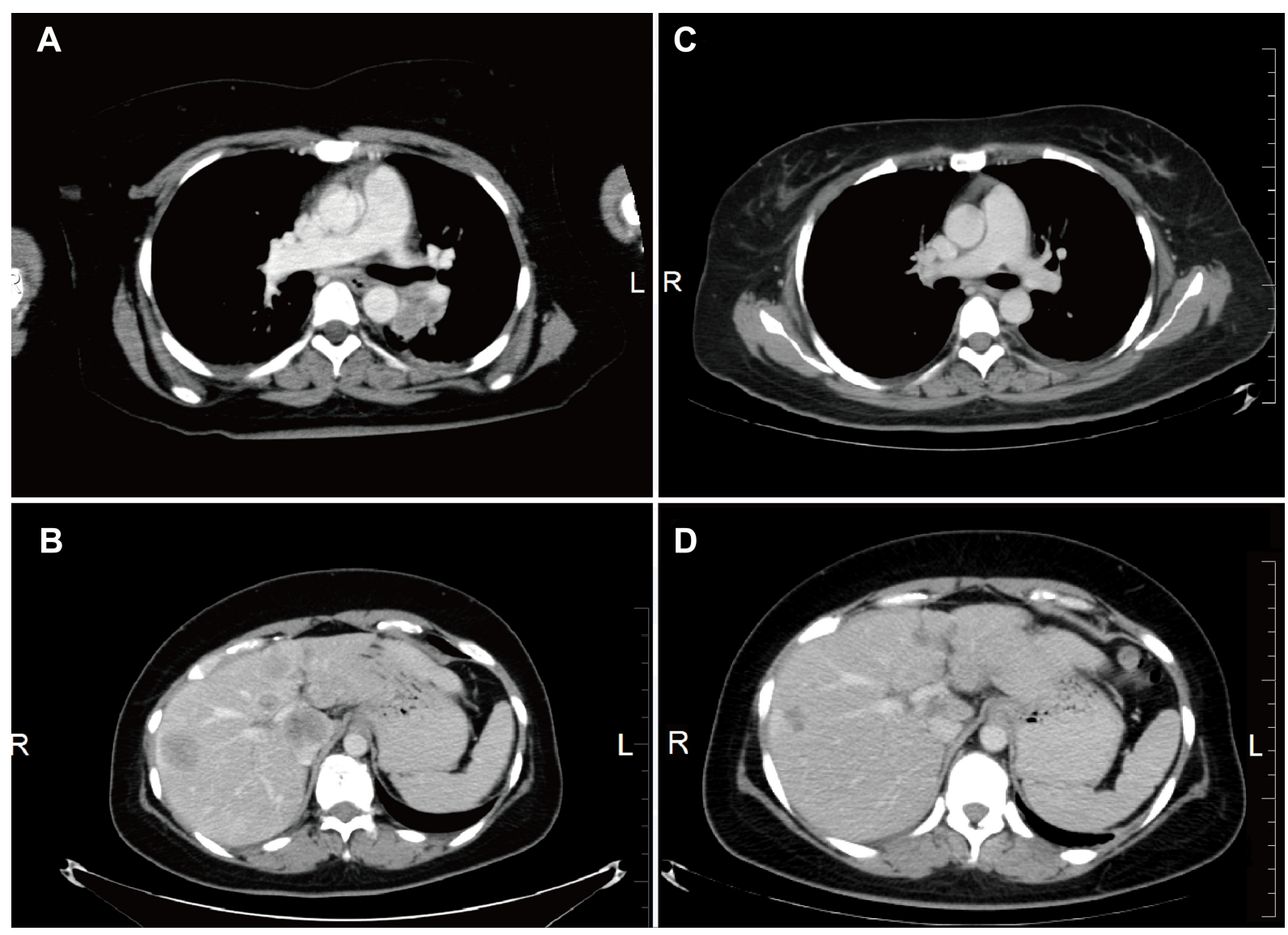

Figure I A computed tomography scan pre-alectinib treatment (A), (B), 4 weeks after starting alectinib, the tumor demonstrated partial response (C), (D). Abbreviations: L, left; R, right. 

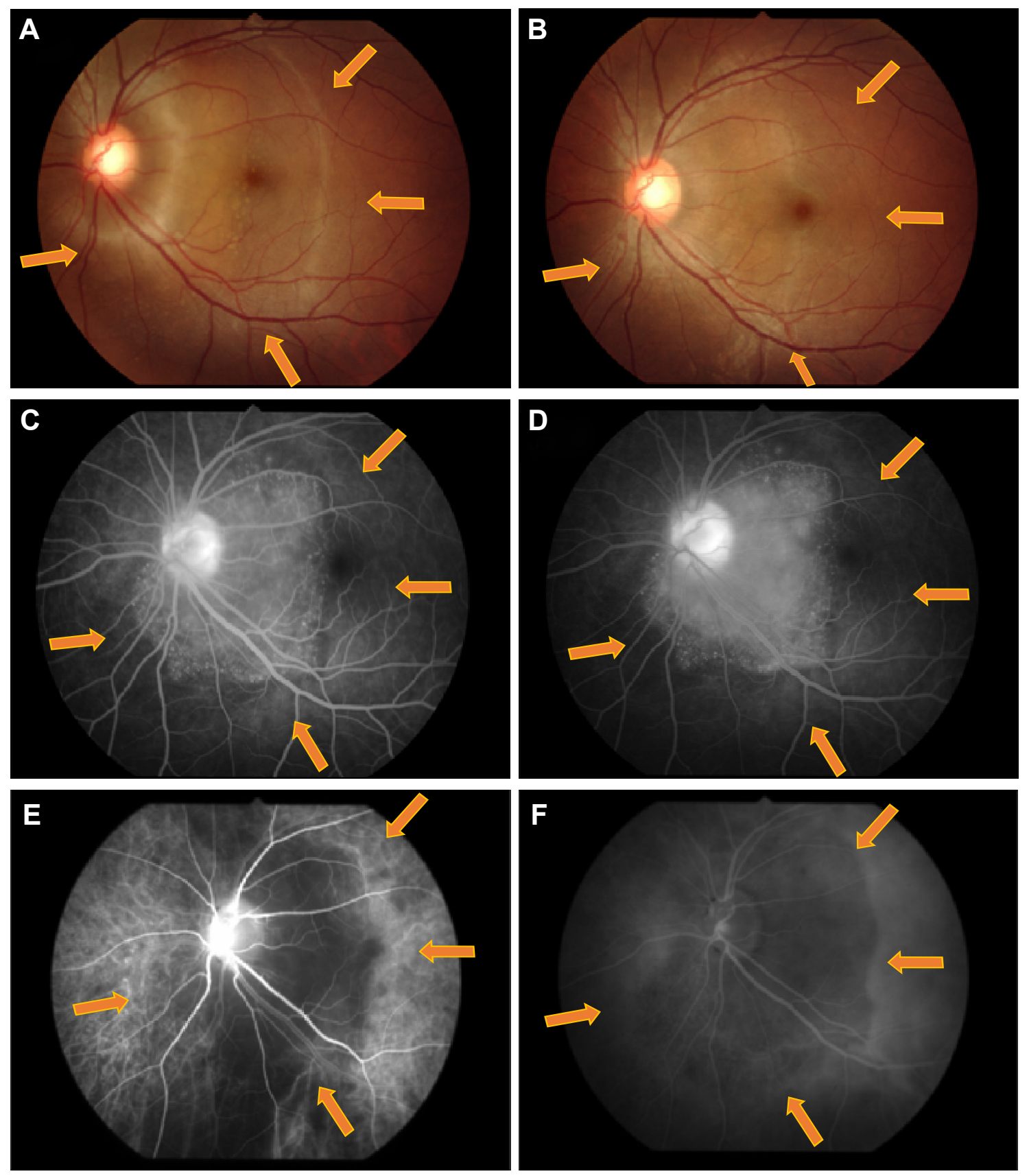

Figure 2 Fundus images.

Notes: Left ocular (A), (B), fluorescence angiography demonstrates late pinpoint hyperfluorescence (C), (D), and indocyanine-green angiography (E), (F). Top row are pre-alectinib (A), (C), (E) images showing a white, elevated lesion with an irregular margin representing retinal detachment with sub-retinal edema (arrows) (A). The bottom row are post-alectinib (B), (D), (F) images showing a decrease in size of the metastatic choroidal lesion after 3 weeks of alectinib treatment. The orange arrows indicate the metastatic lesions.

cases and are generally unilateral solitary lesions in the left eye; however, the prevalence of symptomatic disease is reported to be less than $3 \% .^{12}$ Therefore, it appears that choroidal metastases are more common than reported on postmortem examination, although visual disturbances do not appear.

The reason that choroidal metastasis is the most frequent site for metastasis in the ocular region appears to be the abundant blood supply, which may present a suitable microenvironment for cancer cell growth. Cancer associated low vision has a differential diagnosis, and we should consider carcinoma associated retinopathy syndrome, brain metastasis, and chemotherapy-induced optic neuropathy in these patients. ${ }^{13}$ Funduscopic examination and electroretinography are useful for diagnosis.

As they are seldom reported, there is no strong consensus regarding the therapeutic strategy for choroidal metastasis. 
Conventionally, treatment for choroidal metastases is ocular radiotherapy or photocoagulation ${ }^{14-16}$ intended for preserving vision. The recommended doses are higher than 35.5 Gy based on a retrospective study on radiotherapy of choroidal metastases; visual acuity was improved or stabilized in $72 \%$ of patients, and deteriorated in $18 \% .{ }^{14}$ Clinical response is reported to have concordance with retinal reattachment examination results. Complications include cataract in $0.04 \%$ and retinopathy and glaucoma in $0.01 \%$ of patients. In patients with secondary glaucoma and poor response to radiation, surgical enucleation is considered, but these may lead to loss of vision and decreased quality of life during the patient's remaining lifespan. Although local therapy results in relatively good outcome with a degree of adverse events, patients with choroidal metastases still have an exceptionally poor prognosis of only 2 months with the 1-, 2-, and 3-year survival rates of $20 \%, 7 \%$, and $0 \%$, respectively. ${ }^{17}$

On the other hand, in the era of molecular targeted therapy, patients harboring actionable drivers are anticipated to survive longer with matched targeted therapy. ${ }^{18}$ Therefore, late toxicity from radiotherapy should be taken into account more than before in the longer survival era even in those with advanced NSCLC. Lethal complications related to the metastatic site should be discussed during treatment management, such as when the central nervous system (CNS) is involved. Oncologists typically select treatment management with consideration for treatment benefits and side-effects so as to not disturb quality of life, especially if treatment failure leads to poor prognosis. One solution is to avoid radiotherapy and replace it with recent molecular targeted treatment. Brain metastasis may be a good example. In the pre-molecular targeted era, generally, cytotoxic chemotherapy has been considered less effective for brain metastases because of the presence of the blood-brain barrier (BBB); therefore, frontline whole brain radiotherapy has often been selected. However, small molecule targeted therapy such as erlotinib ${ }^{7}$ and pemetrexed ${ }^{19}$ pass the BBB and are reported to be effective for brain metastasis as well as thoracic lesions. Therefore, the recent consensus on the management of brain metastasis suggests that upfront whole brain radiotherapy is not always required. ${ }^{20}$ Likewise, choroidal vasculature is considered to hamper the delivery of chemotherapy to choroidal metastases; therefore, radiotherapy has been recommended, as reviewed earlier in this article. However, the choroidal vasculature exhibits the highest blood flow among ocular tissues and its endothelium has numerous fenestrations, whereas the retina has a tight junction complex to create a barrier similar to the BBB in the CNS. Therefore, large macromolecules can leak out of the vessels. ${ }^{21}$ There have been some anecdotal reports of complete remission of choroidal metastases with chemotherapy alone $^{22}$ or molecular targeted therapy. Recent reports have demonstrated the efficacy of intravitreal bevacizumab. ${ }^{23-25}$ In the longer survival era of molecular targeted therapy, upfront chemotherapy is one of the options for choroidal metastasis and radiotherapy may be preserved as a later treatment option.

$A L K$ rearranged in NSCLC as in the patient of this present report, is one of the noted rare subtypes of oncogenic drivers accounting for approximately $5 \%$ of cases. ${ }^{26}$ Targeted therapies for advanced $A L K$ rearranged NSCLCs have been developed and show a higher response and longer response duration than cytotoxic chemotherapy, by the first-generation ALK inhibitor, crizotinib ${ }^{27}$ and the second-generation, alectinib $^{28}$ or ceritinib. ${ }^{29}$ More specifically, alectinib is a novel small molecule receptor tyrosine kinase inhibitor for $A L K$ rearranged NSCLC with a response rate of $93.5 \%$ in two Phase I/II trials. In crizotinib-resistant cases, a 55\% overall response rate, including a 52\% response rate of CNS metastasis, was observed with alectinib. ${ }^{30}$ Therefore, considering the risk of late toxicities and the previous crizotinib-resistance, the patient received alectinib treatment without radiotherapy at diagnosis of choroidal metastasis.

We observed improvement of low vision and retinal detachment following alectinib treatment. The choroidal metastasis in this patient would have likely been missed if she had undergone crizotinib treatment with the visual disturbance.

In summary, in the era of longer survival with driver mutation directed therapies, small molecule receptor tyrosine kinase inhibitors, including alectinib, may be a treatment option for $A L K$ rearranged NSCLC patients presenting with choroidal metastases. However, we should keep in mind nonresponder cases, which do not often appear in the literature because of publication bias.

\section{Conclusion}

Choroidal metastasis is a rare type of metastasis and no strong recommended standard of care is established, however, alectinib was active for ALK rearrangement NSCLC having choroidal metastasis similar to other small molecule targeted agents.

\section{Disclosure}

The authors report no conflicts of interest in this work. 


\section{References}

1. Postmus PE, Brambilla E, Chansky K, et al. The IASLC Lung Cancer Staging Project: proposals for revision of the $\mathrm{M}$ descriptors in the forthcoming (seventh) edition of the TNM classification of lung cancer. J Thorac Oncol. 2007;2(8):686-693.

2. Shields CL, Shields JA, De Potter P, et al. Plaque radiotherapy for the management of uveal metastasis. Arch Ophthalmol. 1997;115(2): 203-209.

3. Freedman MI, Folk JC. Metastatic tumors to the eye and orbit. Patient survival and clinical characteristics. Arch Ophthalmol. 1987; 105(9):1215-1219.

4. Kanthan GL, Jayamohan J, Yip D, Conway RM. Management of metastatic carcinoma of the uveal tract: an evidence-based analysis. Clin Experiment Ophthalmol. 2007;35(6):553-565.

5. Wang TJ, Yang CM, Ho TC, et al. Metastatic choroidal tumors in Taiwan: an 11-year experience. Am J Ophthalmol. 2005;140(4):735-737.

6. Jardel P, Sauerwein W, Olivier T, et al. Management of choroidal metastases. Cancer Treat Rev. 2014;40(10):1119-1128.

7. Gerber NK, Yamada Y, Rimner A, et al. Erlotinib versus radiation therapy for brain metastases in patients with EGFR-mutant lung adenocarcinoma. Int J Radiat Oncol Biol Phys. 2014;89(2):322-329.

8. Lu S, Azada MC, Ou SH. Choroidal metastasis response to crizotinib in a ROS1-rearranged NSCLC patient. Lung Cancer. 2015;87(2): 207-209.

9. Eisenhauer EA, Therasse P, Bogaerts J, et al. New response evaluation criteria in solid tumours: revised RECIST guideline (version 1.1) Eur J Cancer. 2009;45(2):228-247.

10. Bloch RS, Gartner S. The incidence of ocular metastatic carcinoma. Arch Ophthalmol. 1971;85(6):673-675.

11. Nelson CC, Hertzberg BS, Klintworth GK. A histopathologic study of 716 unselected eyes in patients with cancer at the time of death. Am J Ophthalmol. 1983;95(6):788-793.

12. Kreusel KM, Wiegel T, Stange M, Bornfeld N, Hinkelbein W, Foerster MH. Choroidal metastasis in disseminated lung cancer: frequency and risk factors. Am J Ophthalmol. 2002;134(3):445-447.

13. Okuma Y, Hosomi Y, Kitamura K, et al. Choroidal metastasis in a patient with small cell lung cancer discovered during treatment with chemotherapy. Int J Clin Oncol. 2009;14(6):541-544.

14. Rosset A, Zografos L, Coucke P, Monney M, Mirimanoff RO. Radiotherapy of choroidal metastases. Radiother Oncol. 1998;46(3):263-268.

15. Mauget-Faysse M, Gambrelle J, Quaranta-El Maftouhi M, Moullet I Photodynamic therapy for choroidal metastasis from lung adenocarcinoma. Acta Ophthalmol Scand. 2006;84(4):552-554.

16. Wiegel T, Bottke D, Kreusel KM, et al. External beam radiotherapy of choroidal metastases - final results of a prospective study of the German Cancer Society (ARO 95-08). Radiother Oncol. 2002;64(1):13-18.

17. Kreusel KM, Bechrakis NE, Wiegel T, Krause L, Foerster MH. Incidence and clinical characteristics of symptomatic choroidal metastasis from lung cancer. Acta Ophthalmol. 2008;86(5):515-519.
18. Kris MG, Johnson BE, Berry LD, et al. Using multiplexed assays of oncogenic drivers in lung cancers to select targeted drugs. JAMA. 2014; 311(19):1998-2006.

19. Barlesi F, Gervais R, Lena H, et al. Pemetrexed and cisplatin as firstline chemotherapy for advanced non-small-cell lung cancer (NSCLC) with asymptomatic inoperable brain metastases: a multicenter phase II trial (GFPC 07-01). Ann Oncol. 2011;22(11):2466-2470.

20. Moscetti L, Nelli F, Felici A, et al. Up-front chemotherapy and radiation treatment in newly diagnosed nonsmall cell lung cancer with brain metastases: survey by Outcome Research Network for Evaluation of Treatment Results in Oncology. Cancer. 2007;109(2):274-281.

21. Cunha-Vaz JG, Shakib M, Ashton N. Studies on the permeability of the blood-retinal barrier. I. On the existence, development, and site of a blood-retinal barrier. Br J Ophthalmol. 1966;50(8):441-453.

22. Yang CJ, Tsai YM, Tsai MJ, Chang HL, Huang MS. The effect of chemotherapy with cisplatin and pemetrexed for choroidal metastasis of nonsquamous cell carcinoma. Cancer Chemother Pharmacol. 2014;73(1): 199-205.

23. Kim SW, Kim MJ, Huh K, Oh J. Complete regression of choroidal metastasis secondary to non-small-cell lung cancer with intravitreal bevacizumab and oral erlotinib combination therapy. Ophthalmologica. 2009;223(6):411-413.

24. George B, Wirostko WJ, Connor TB, Choong NW. Complete and durable response of choroid metastasis from non-small cell lung cancer with systemic bevacizumab and chemotherapy. J Thorac Oncol. 2009; 4(5):661-662.

25. D'Antonio C, Viterbo A, Romiti A, Enrici MM, Lauro S, Marchetti P. Complete regression of a non-small cell lung cancer choroidal metastasis with intravitreal bevacizumab. J Thorac Oncol. 2012;7(2):468-469.

26. Shaw AT, Engelman JA. ALK in lung cancer: past, present, and future J Clin Oncol. 2013;31(8):1105-1111.

27. Shaw AT, Kim DW, Nakagawa K, et al. Crizotinib versus chemotherapy in advanced ALK-positive lung cancer. N Engl J Med. 2013; 368(25):2385-2394

28. Seto T, Kiura K, Nishio M, et al. CH5424802 (RO5424802) for patients with ALK-rearranged advanced non-small-cell lung cancer (AF-001JP study): a single-arm, open-label, phase 1-2 study. Lancet Oncol. 2013; 14(7):590-598.

29. Shaw AT, Kim DW, Mehra R, et al. Ceritinib in ALK-rearranged nonsmall-cell lung cancer. N Engl J Med. 2014;370(26):1189-1197.

30. Gadgeel SM, Gandhi L, Riely GJ, et al. Safety and activity of alectinib against systemic disease and brain metastases in patients with crizotinibresistant ALK-rearranged non-small-cell lung cancer (AF-002JG) results from the dose-finding portion of a phase 1/2 study. Lancet Oncol. 2014;15(10):1119-1128.
OncoTargets and Therapy

\section{Publish your work in this journal}

OncoTargets and Therapy is an international, peer-reviewed, open access journal focusing on the pathological basis of all cancers, potential targets for therapy and treatment protocols employed to improve the management of cancer patients. The journal also focuses on the impact of management programs and new therapeutic agents and protocols on

\section{Dovepress}

patient perspectives such as quality of life, adherence and satisfaction. The manuscript management system is completely online and includes a very quick and fair peer-review system, which is all easy to use. Visit http://www.dovepress.com/testimonials.php to read real quotes from published authors. 